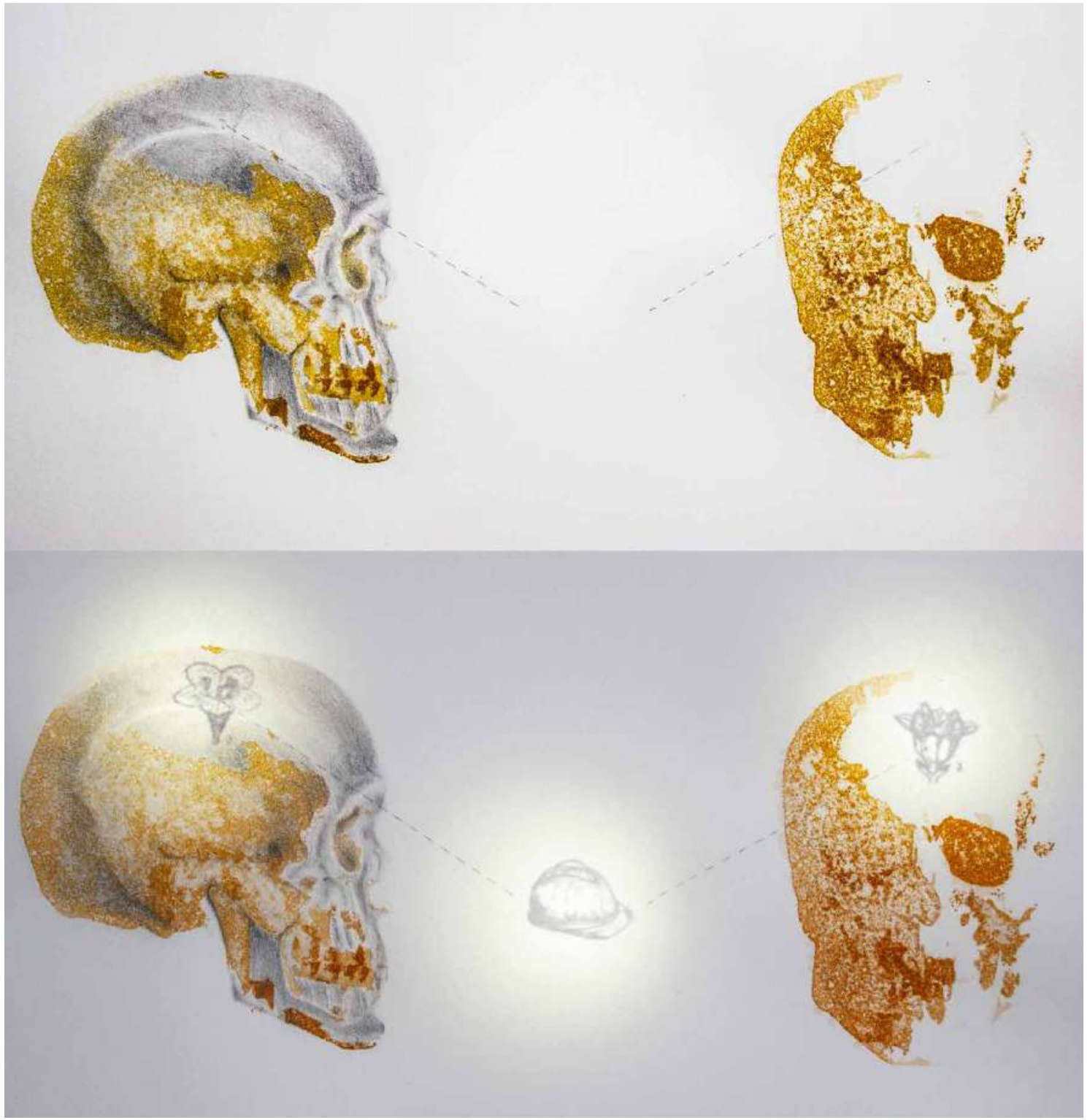

Yamith Quiroz David

Estudio 3

De la serie Herrumbres, cuerpos desechos

Dibujo con óxido ferroso, tinta, luz led cálida sobre papel Arches

$33,5 \times 43,5 \times 7 \mathrm{~cm}$

2020

Medellín 


\title{
«Son gente como yo». Brókeres y construcción de maquinaria política en la ciudad de Palmira, Valle del Cauca, Colombia (2008-2019)*
}

\author{
Camilo Ernesto Serrano Corredor (Colombia)**
}

\section{Resumen}

La continuidad local de facciones políticas con fuertes maquinarias electorales en la Colombia posterior a la reforma política de 2003 es aún un campo relativamente inexplorado. El presente trabajo contribuye a la discusión de este tema a partir de un estudio de caso, el del caicedismo en Palmira durante el periodo de su acceso a la Alcaldía, 2008-2019. Se explica este fenómeno a partir del proceso de construcción de maquinaria política por parte de los líderes: intermediarios electorales o brókeres. Para ello se hace uso de la inmersión etnográfica centrada en dichos actores y en las actividades de campaña del caicedismo en las elecciones locales de 2019. Se concluye que los intermediarios electorales fueron actores clave del proceso de construcción de la maquinaria de la facción caicedista en Palmira en su acceso al poder local y su comportamiento reta las construcciones teóricas habituales en este campo.

\section{Palabras clave}

Cultura Política; Política Subnacional; Clientelismo; Intermediario Electoral; Maquinaria Política; Colombia.

Fecha de recepción: octubre de 2019

- $\quad$ Fecha de aprobación: abril de 2020

\section{Cómo citar este artículo}

Serrano Corredor, Camilo Ernesto. (2020). "Son gente como yo». Brókeres y construcción de maquinaria política en la ciudad de Palmira, Valle del Cauca, Colombia (2008-2019). Estudios Políticos (Universidad de Antioquia), 59, pp. 227-251. DOI: 10.17533/udea.espo.n59a10

\footnotetext{
* Este artículo se enmarca en un proyecto más amplio, La campaña electoral de Nueva Generación en las elecciones legislativas de 2018: ambición, trayectorias y mediadores electorales en Cali y Palmira, adscrito a la Facultad de Derecho y Ciencias Sociales de la Universidad Icesi, Colombia, 2018-2019.

${ }^{* *}$ Licenciado en Historia. Profesor e investigador del Departamento de Estudios Políticos, Facultad de Derecho y Ciencias Sociales, Universidad Icesi, Colombia. Correo electrónico: camilo.serrano@, correo.icesi.edu.co - Orcid: 0000-0002-5051-4603 - Google Scholar: https://scholar.google.com/citati ons?user $=$ s9qXVdAAAAAJ $\&$ hl $=$ es
} 


\title{
«They are People Like Me». Brokers and Political Machine-Building in Palmira, Valle del Cauca, Colombia
}

\begin{abstract}
The local persistence of political factions strongly linked with political machines in contemporary Colombia is still an unexplored field. This article contributes to that debate through a case study: the so-called Caicedismo in Palmira, Valle del Cauca, during its period in the local office (2008-2019). This process is explained through the political machine-building carried out by the Caicedismo's leaders (brokers). For this aim, ethnographic immersion was implemented, mainly centered in Caicedismo's brokers and their campaign activities during 2019 local elections. It is concluded that the electoral brokers were key actors in the process of building the political machine of the Caicedista faction in Palmira for their access to local power, and also that their behavior challenges the usual theoretical constructions in this field.
\end{abstract}

\section{Keywords}

Political Culture; Subnational Politics; Clientelism; Broker; Political Machine; Colombia. 


\section{Introducción}

Los análisis de la política subnacional colombiana requieren de un mayor acervo empírico, particularmente en lo relativo a los actores directamente implicados en el día a día. A pesar del incremento en estudios de caso a profundidad, lo que ocurre en la política de provincias, particularmente en municipios pequeños e intermedios, parece pasar simplemente porque sí.

Este texto aporta a dicha comprensión a partir de la reconstrucción de las actividades particulares de los intermediarios electorales de un caso exitoso de relación entre facción política, construcción de maquinaria y acceso y permanencia al poder local: el caicedismo en la ciudad de Palmira, departamento del Valle del Cauca, Colombia. Dicho movimiento accedió a la Alcaldía a partir de las elecciones de 2007, primeras de su tipo ocurridas tras la implementación del Acto Legislativo 01 de 2003, más conocido como reforma política de 2003, el cual reconfiguró el régimen de partidos en Colombia. A partir de allí logró reelegirse en otras dos ocasiones.

Para el logro de sus objetivos, el presente estudio centra su análisis en dos tipos de evidencia: los testimonios de intermediarios electorales líderes_y la observación de la campaña electoral de 2019.

\section{Contexto}

\subsection{La ciudad de Palmira}

Palmira es la segunda ciudad del departamento del Valle del Cauca y un importante nodo agroindustrial, comercial y de transporte del suroccidente colombiano. Se encuentra ubicada en la franja oriental del valle geográfico del río Cauca, ascendiendo por la cordillera Central, en donde limita con el departamento del Tolima. Tiene una extensión de 1028 km² y una población aproximada de 310000 habitantes (Cámara de Comercio de Palmira, 2017). Para 2017, el municipio tenía un valor agregado municipal de 5657 millones de pesos, equivalente a 6,98\% del valor agregado departamental, solo superado por la capital, Cali, y el municipio industrial de Yumbo (DANE, 2019). En Palmira se concentran varios de los ingenios azucareros más importantes del país, así como un considerable cinturón industrial y de servicios, una zona franca y el aeropuerto internacional que sirve a Cali.

Políticamente, Palmira fue un fortín liberal desde el siglo xix. Los palmiranos participaron de los ejércitos liberales en las guerras civiles 
decimonónicas (Valencia, 2019, pp. 82-98), incluso la Guerra de las Escuelas de 1876 dio inicio con una escaramuza armada en inmediaciones de Palmira (Guerrero Apráez, 2013, p. 564). Ya en la violencia bipartidista del siglo xx el municipio fue escenario de acciones armadas, asesinatos selectivos y refugio de guerrilleros liberales (Delgado, 2011). Tal ligazón con el Partido Liberal llevó a que alcanzara el mote de «plaza roja de Colombia» (El Tiempo, 2006, enero 16), en referencia a los colores del partido.

Durante el siglo xxı, el escenario político palmirano ha estado marcado por la consolidación de redes clientelares muy significativas como el caicedismo, el motoísmo ${ }^{1}$ y el agudelismo. ${ }^{2}$

La tradición política palmirana es hija del trapo rojo, de lo que fue «Palmira, la Plaza Roja de Colombia», es la Casa Liberal que hoy es la casa de Cambio Radical [...]. Entonces todos aquí somos hijos del trapo rojo, de esos grandes políticos de plaza, los Kuri, los Motoa, los Orejuela, toda esa gente que fueron los liberales que hicieron que [...] ningún candidato [presidencial] liberal se atrevió a no venir a Palmira o no darle una fecha importante a la manifestación política en Palmira. [...Las grandes familias liberales son] los Motoa, los Kuri, los Agudelo, [...] los Orejuela de Raúl Orejuela Bueno. Claro que estos que te menciono son casi que centenarios, históricos, son liberales desde la mitad del siglo xx. Los Caicedo son más ochentas y noventas. Los Agudelo igual. Digamos que las dos últimas grandes familias del liberalismo son los Motoa y los Kuri, que están emparentadas de hecho entre ellas (analista local, comunicación personal, julio 18, 2019).

\subsection{El caicedismo}

El caicedismo surgió en Palmira como la ramificación local del movimiento Nueva Generación, facción del Partido Social de Unidad Nacional, mejor conocido como Partido de la U. Proviene de la facción becerrista del Partido Liberal, una de sus más importantes facciones en el Valle del Cauca durante las décadas de 1980 y 1990. Surgió con el nombre de Fuerza Liberal

\footnotetext{
${ }^{1}$ Maquinaria política de origen liberal cuyo liderazgo histórico recayó en Miguel Motoa Kuri varias veces concejal del municipio, así como su alcalde en 2001-2003, también congresista en varios periodos - y que ingresó al partido Cambio Radical en el siglo en curso. Conserva la tradicional Casa Liberal de Palmira y representación en el Congreso vía Carlos Fernando Motoa, su hijo, quien es senador activo.

${ }^{2}$ Maquinaria política de origen liberal dirigida por la familia Agudelo Londoño. Con la llegada del siglo en curso y de la Reforma Política de 2003, pasaron por varios avales - Cambio Radical, Centro Democrático y Partido Liberal- . Actualmente, cuentan con un concejal bajo el Partido Liberal: Jorge Enrique Agudelo.
} 
Socialdemócrata hacia 1984 bajo el liderazgo de Manuel Francisco «Kiko» Becerra, siendo una escisión de la facción holmista. Durante su auge de la década de 1990, el becerrismo logró representación legislativa, varias alcaldías y un número significativo de concejales y diputados (Gaitán, s. f.). La vinculación penal de Becerra en 1997 terminó afectando la permanencia de su protagonismo político al interior del Partido Liberal (Murillo, 2015). El sector mayoritario del becerrismo, liderado por Dilian Francisca Toro y los hermanos Caicedo Zamorano, fundó Nueva Generación, el cual se vinculó al Partido de la U.

Bajo el liderazgo de Dilian Francisca Toro y de los hermanos Julio César y Jorge Enrique Caicedo Zamorano — Nueva Generación- se convirtió en una de las facciones más importantes del Partido de la $U$ en todo el país. Si bien Nueva Generación y el caicedismo constituyen una única facción, incluso los intermediarios de Palmira suelen hablar indistintamente de las dos, en la práctica hay notables diferencias (Duque, 2018, febrero 18; 2019, octubre 2), como resultó patente en el desarrollo de la presente investigación. Como señaló un líder de Nueva Generación de Cali: «los caicedistas allá y nosotros acá» (comunicación personal, abril 28, 2019).

En ese marco, el caicedismo en Palmira logró pasar de la minoría en el Concejo a ser la principal facción local. Usando una creciente red de alianzas alcanzó tres gobiernos locales consecutivos —Raúl Arboleda (2008-2011), Ritter López (2012-2015) y Jairo Ortega Samboní (2016-2019)— a través de los cuales amplió su incidencia local en el Concejo, la Asamblea Departamental y el Congreso. La evolución de las votaciones del caicedismo resulta significativa.

Tabla 1. Votaciones del caicedismo

en las elecciones locales de Palmira, 2007-2019.

\begin{tabular}{|l|c|c|c|c|c|c|}
\hline Año & Alcaldía & $\begin{array}{c}\text { Porcentaje } \\
\text { Alcaldía }^{-}\end{array}$ & Concejo $^{3}$ & $\begin{array}{c}\text { Porcentaje } \\
\text { Concejo }\end{array}$ & $\begin{array}{c}\text { Concejales } \\
\text { electos }\end{array}$ & $\begin{array}{c}\text { Porcentaje } \\
\text { Concejo }\end{array}$ \\
\hline 2007 & 39247 & 35,33 & 21357 & 18,16 & 5 & 26,3 \\
\hline 2011 & 56889 & 49,84 & 40278 & 34,44 & 9 & 47,4 \\
\hline 2015 & 71151 & 55,5 & 52814 & 39,29 & 10 & 52,6 \\
\hline $2019^{4}$ & 59973 & 39,97 & 52547 & 36,08 & 9 & 47,4 \\
\hline
\end{tabular}

Fuente: elaboración propia con datos de la Registraduría.

\footnotetext{
${ }^{3}$ Se incluyen solamente resultados de las listas del Partido de la U. Se debe tener en cuenta que desde las elecciones de 2011 el caicedismo también presentó candidatos a través de otros partidos.

${ }^{4}$ Resultados parciales al 28 de octubre de 2019. El caicedismo perdió la Alcaldía, pero mantuvo las mayorías del Concejo.
} 


\subsection{Los estudios sobre Nueva Generación y el caicedismo}

A pesar de su incidencia política regional, Nueva Generación y el caicedismo han sido objeto de poca reflexión académica. Un primer cuerpo de estudios ha analizado la incidencia departamental del antiguo becerrismo desde su surgimiento en 1984 hasta su crisis derivada de la vinculación penal de Manuel Francisco Becerra en 1997, en momentos en que la facción vivía un alto pico de representación política departamental (Murillo, 2015; Sáenz, 2010; Gaitán, s. f.).

De otro lado, se han analizado las capacidades de Nueva Generación para seleccionar sus candidatos y definir su estrategia electoral, caracterizando a la facción como «altamente institucionalizada y [...] una de las pocas con capacidad de lograr más de un escaño tanto en la Asamblea Departamental como en el Concejo de Cali», una corriente de corte vertical que cuenta con una alta reciprocidad en la transferencia de votos, excediendo incluso al Partido de la U (Milanese y Barrero, 2016, p. 79).

Finalmente, estudios recientes aportan sobre el plano local: Tania Arce (2018) estudia el comportamiento electoral del caicedismo en Palmira; y Ana

[232] García y Anderson Gaviria (2015) analizan las redes clientelares de Nueva Generación en Guacarí.

\section{Enfoque teórico}

\subsection{Clientelismo y sistema político}

El sistema político colombiano ha sido caracterizado como desinstitucionalizado, fragmentado y electoralmente volátil (Albarracín, Gamboa y Mainwaring, 2018). Dentro de él, las prácticas clientelares ocupan un lugar central, siendo objeto de diversos enfoques (Guerrero García, 2014). Trabajos recientes al respecto sustentan la pertinencia de ahondar en el concepto (Zapata, 2016a; Pino y Cárdenas, 2016; De León, 2011; García y Revelo, 2010), respondiendo a la clásica conclusión: se necesitan más y mejores trabajos sobre el tema (Dávila, 1999).

Dos conclusiones de dicho debate resultan de gran utilidad para el presente estudio: de un lado, la comprensión del clientelismo como un fenómeno que constituye una especie de sistema en sí mismo (Leal y Dávila, 2010; Dávila, 1999); del otro, la interesante agenda de investigación que 
abre Gloria Isabel Ocampo (2014) y su «etnografía del poder», enfocada en el plano subnacional del clientelismo y la relación clientelas regionalesGobierno central.

Finalmente, es de resaltar la existencia de un cuerpo creciente de estudios enfocados en el clientelismo subnacional (González, Guzmán y Tuirán, 2019; Gallego, 2018; Zapata, 2016b). Avances en esta dirección pueden permitir superar dos barreras: la complejidad de la relación entre clientelismo y política subnacional (Durazo, 2012), y la pervivencia de la comprensión del ejercicio de la democracia subnacional como una cuestión inexplicable (Cendales, Guerrero, Wilches y Pinto, 2019, p. 3).

\subsection{Maquinaria política local y facción política}

Una definición clásica de maquinaria política señala que se trata de una organización partidaria con un poder centralizado en donde priman los incentivos materiales sobre la ideología (Johnston, 1979, p. 385). Sus objetivos son la consecución y garantía de cargos para sus líderes y la distribución de ingresos para quienes trabajan por ella (Scott, 1969, p. 1144). En últimas, las maquinarias políticas se enfocan en la autopreservación y la acumulación de poder, para lo cual requieren de eficacia electoral (Núñez, 2018, p. 110) que garantice incentivos suficientes para mantener «el control sobre la autoridad pública» (Johnston, 1979, p. 385).

A su vez, por facción política se entiende todo «agrupamiento o combinación al interior de un partido cuyos miembros comparten un sentido de identidad común y están organizados para actuar colectivamente» (Zariski, 1960, p. 33). Se distinguen por un carácter marcadamente personalista centrado en la figura de sus dirigentes (Cendales, Olaya y Duncan, 2019, p. 28). Un estudio reciente sobre el caso colombiano concluye que estas estructuras crean identidades propias signadas por la entronización de liderazgos personales alrededor de los cuales se teje la compleja trama de redes del ámbito subnacional (Cendales, Guerrero, Wilches y Pinto, 2019, p. 27).

Igualmente, estudios recientes analizan la relación entre estos conceptos y poder local, presentando conclusiones interesantes para este trabajo: Andrés Cendales, Jorge Olaya y Gustavo Duncan (2019) se enfocan en la relación entre facción local, Alcaldía y calidad de la política pública local; Lucas Núñez (2018) estudia el comportamiento de una facción electoral 
efectiva con acceso al poder local, señalando dos posibles consecuencias del mantenimiento del control sobre la Alcaldía: a) tener mayores ventajas para obtener una Alcaldía consecutiva, y b) tener efectos de arrastre o de arrastre inverso sobre copartidarios compitiendo para otros cargos.

Finalmente, es de destacar el interés teórico de Simeon Charaka Nichter (2010, pp. 57-81) por construir una tipología formal del clientelismo.

\subsection{Los intermediarios electorales en perspectiva}

En este artículo se entiende como intermediario electoral o bróker al líder local que provee beneficios específicos y resuelve problemas a sus seguidores o bases sociales, solicitando en retribución la participación en actividades políticas como manifestaciones, reuniones o incluso pidiéndoles el voto por un candidato o partido concreto (Stokes, Dunning, Nazareno y Brusco, 2013, p. 74). En el argot político del Valle del Cauca los brókeres son usualmente denominados líderes.

La literatura sobre intermediarios tiende a dividirse en dos vertientes: la acción normativa —el bróker sigue una norma preestablecida- y el actor [234 ] racional —el bróker calcula la maximización de sus beneficios—(Auyero, 1996, pp. 216-217). Un tercer enfoque —el informacional— ha sido construido por Paula Muñoz (2014) a partir de la evidencia del caso peruano, centrándose en el movimiento de información sobre capacidades de los candidatos y de los brókeres; sin embargo, Mark Schneider (2019) señala que, a pesar de las ventajas de los brókeres como conocedores de primera mano de las posibles preferencias de sus potenciales votantes, no necesariamente dicha información es sustancial. Por su parte, Nichter (2010) reconoce dos tipos de clientelismo: el relacional —los beneficios pueden favorecer al votante incluso después de la votación y pueden ocurrir defecciones oportunistas tanto del votante como de los dirigentes - y el electoral — los beneficios se distribuyen antes de las votaciones y el sujeto de la defección oportunista es solo el potencial votante-.

Bajo una óptica similar, Susan Stokes, Thad Dunning, Marcelo Nazareno y Valeria Brusco (2013) sostienen que la capacidad del intermediario de conformar su propio grupo de seguidores y de manejar información privilegiada determina el balance de poder con su respectivo dirigente, para ello requiere reputación y habilidades para lograr traducir regulaciones inciertas en intervenciones viables (Kadfak, 2019). Así, movilizaciones masivas, marchas o 
discursos de plaza pública adquieren un valor particular: son demostraciones de la fuerza y popularidad de los candidatos, al tiempo que un mecanismo de control a la influencia de los brókeres (Muñoz, 2014, pp. 84-86).

Finalmente, existe la propuesta de centrar el análisis en un terreno empírico inexplorado: las estrategias utilizadas por los intermediarios y la manera como estas se transmiten (Auyero y Benzecry, 2016; Auyero, 1996). La conclusión de los avances en esta tarea es centrar la investigación en el testimonio mismo de los brókeres, escuchar sus voces, acompañar su cotidianidad y acercarse al «punto de vista clientelar» (Auyero, 1996; 2001), pasando la etnografía a desempeñar un papel cardinal. En ese sentido, un buen número de trabajos recientes han cubierto dicho silencio (Eufracio, 2019; Kadfak, 2019; Berenschot y Bagchi, 2019; Hagene, 2018; Pérez y Luján, 2018; Ortiz, 2017; Muñoz, 2014; Zarazaga, 2014).

\section{Metodología}

\subsection{Modelo}

El presente trabajo obedece a la señalada necesidad de centrar el enfoque de las investigaciones de clientelismo en la experiencia misma de los actores que vivencian, reproducen y transforman estructuras ubicadas en los intersticios de la política real, en donde la disponibilidad de información agregada dificulta metodologías cuantitativas. Coincide entonces con la conclusión de Muñoz (2014, p. 81): la urgencia de estudios cualitativos sobre el clientelismo para alcanzar estudios en profundidad sobre un fenómeno elusivo. Asimismo, asume la recomendación de John Gerring (2012): cuando algún elemento de misterio está involucrado, «ir a lo local» es lo más indicado, cobrando importancia la inmersión etnográfica, con sus ventajas y limitaciones. En ese mismo sentido, el involucramiento del autor —nativo de Palmira y acostumbrado a su peculiar cultura política - se relaciona con la mediación de los informantes.

Se realizaron quince entrevistas semiestructuradas a personas con distintos perfiles: intermediarios y candidatos caicedistas, funcionarios públicos y analistas de la política local. Adicionalmente, como parte de un proyecto de investigación más amplio, se entrevistaron a intermediarios de Nueva generación y de una facción rival en Cali. Las entrevistas partieron de la necesidad de reconstruir asuntos como la manera de vinculación de los brókeres al movimiento, su permanencia en él, su vida cotidiana como líderes, 
la relación con los dirigentes y las trayectorias ideales y proyecciones de su trabajo. La construcción de narrativas y mecanismos causales se contrastó con varios de los entrevistados durante el proceso del trabajo de campo. Igualmente, se acompañó a eventos de campaña de candidatos caicedistas a la Alcaldía y al Concejo de Palmira entre febrero y octubre de 2019. Es de resaltar que dicho acompañamiento facilitó la inmersión con el entorno de la facción y con el debate político local en boga durante el periodo de estudio.

Finalmente, por los objetivos y metodología propios de este estudio, se hace abstracción de procesos complejos que deben abordarse en un estudio más amplio: a) la naturaleza del Gobierno central y su relación con las facciones subnacionales, y b) la relación entre facción local y Gobernación del Valle del Cauca.

\subsection{Selección de caso}

La escogencia del caso Palmira y el caicedismo se deriva de su comportamiento extremo dentro de lo usual para las maquinarias locales y su continuidad en las alcaldías a partir de la reforma política de 2003. Al analizar la permanencia de facciones políticas en las alcaldías de los veintiún

[236] municipios intermedios de Colombia —aquellos con población entre 250 001 y 1000000 de habitantes - a partir de dicha reforma, solamente en Palmira y Montería se alcanzaron dos reelecciones consecutivas (Registraduría Nacional del Estado Civil (s. f.).

\section{El caicedismo por dentro}

\subsection{Un tipo particular de maquinaria}

A partir de las entrevistas a intermediarios e informantes de Palmira y Cali se construyeron dos tipos de maquinaria local: por un lado, el caicedismo en Palmira se organizó sin una adscripción territorial específica. Las células como se autodenominan las estructuras organizativas de base- se disputan liderazgos y votos sin distinción de territorio, en una suerte de «mercado libre electoral», cuya dirección superior es ocupada por los hermanos Caicedo Zamorano y Ritter López. Se denominó a este tipo de maquinaria como horizontal-competitiva. En este, el ascenso de los líderes obedece a una meritocracia basada en la demostración de capacidades para conseguir votos y de ejercer liderazgo — «saber entender espacios y tiempos», en palabras de un intermediario (intermediario 1, comunicación personal, mayo 29, 
2019) — . Saltarse esa trayectoria ideal, no disponerse a hacer cola, es motivo de expulsión para los líderes de base.

En contraste, Nueva Generación en Cali se organizó en torno a lo que se denominó una maquinaria vertical-territorial: en cada comuna hay un gestor que coordina a sus respectivos jefes de puesto electoral, sin poder realizar actividad política alguna por fuera del territorio asignado. El esquema ideal de ascenso de los brókeres es el siguiente: de líder de base se puede pasar a jefe de puesto y luego a gestor de comuna.

Volviendo al caso de Palmira, las células se construyen en torno a un liderazgo reconocido y distribuyen tareas a simpatizantes y militantes. Se enfocan en actividades como: «trabajo social», campañas electorales, administración pública y relacionamiento permanente con «familia y amigos». El factor común de estas células es la observación de una alta disciplina y el respeto por sus máximos dirigentes. Los concejales son activos organizadores de las células y cada uno dirige por lo menos una, la cual funciona como la base de su propio respaldo político.

La célula puede funcionar también para la resolución de otras necesidades políticas: es un espacio de sociabilidad en donde los líderes se conocen e interactúan, incluso algunas de ellas surgen de colectivos de afinidad con aspiraciones políticas, como el grupo Mega. ${ }^{5}$ Es un mecanismo de control que permite supervisar quién cumple sus compromisos y quién no, e incluso puede funcionar como espacio de autoafirmación, como se concluye del testimonio de una joven lideresa que manifiesta que su célula es un lugar para «sentirse plena» (lideresa caicedista 2, comunicación personal, mayo 29, 2019).

Como se ve, las células caicedistas parecen contravenir el ya clásico esquema de Javier Auyero (2001, pp. 104-109) sobre los círculos concéntricos de incidencia y mediación de los intermediarios.

Finalmente, durante el trabajo de campo se reveló la existencia de un grupo de veteranos dirigentes caicedistas al que un bróker denominó como

${ }^{5}$ Grupo de profesionales que se originó como tertulia política en una panadería local — de la que deriva su nombre- y se transformó en exitosa célula caicedista con concejal propio (analista local, comunicación personal, junio 15, 2019). 
«El Generalato» o «Sanedrín» que, si bien no son activos en política electoral, actúan como consejeros políticos de la dirección superior del movimiento.

\subsection{Un tipo particular de intermediario}

A partir de los testimonios y la observación se construyó una tipología de las actividades diarias de los intermediarios de la maquinaria caicedista. El primer eje articulador de la actividad de los brókeres se resume en la frase de un intermediario, al interpelársele por las motivaciones de selección de su facción: son gente como yo (intermediario 2, comunicación personal, 15 de mayo de 2019). Esta se volvió una idea recurrente durante el trabajo de campo: el peso de la identidad con la trayectoria del dirigente. Para los brókeres, el caicedismo es un buen lugar para ser líder y ascender a través del trabajo duro y disciplinado, siguiendo trayectorias ideales como las de Ritter López o Jairo Ortega Samboní, que fueron líderes de base, luego funcionarios públicos de bajo nivel y ascendieron en la maquinaria hasta ser dirigentes respetados y con ascendencia local. Existe entre los brókeres una expectativa de similitud entre sus trayectorias y las de los dirigentes, resultando muy similar a la conclusión de Taylor Boas y Amy Smith (2019) frente al caso brasilero: se ven como yo, piensan como yo.

El interés por el carácter popular y esforzado de los dirigentes políticos parece ser una impronta de los intermediarios caicedistas: rechazan a candidatos «de élite» o consideran negativo que un intermediario ascienda sin probarse en las diversas tareas del movimiento — de nuevo, «saltarse los espacios y tiempos»—. En el mismo sentido, los líderes señalaron la dificultad de impulsar en su base electoral candidaturas presidenciales percibidas como «de elite», como ocurrió con la candidatura presidencial de Germán Vargas Lleras.

El carácter personalista de la estructura es fuerte: es patente el respeto que suscitan los Caicedo, Dilian Francisca Toro y quien es hoy el líder más visible del movimiento, el exalcalde y senador Ritter López. En torno a la figura de este último se tejió una interesante narrativa de la recuperación del protagonismo del municipio sobre la que se ahondará seguidamente, pero que puede resumirse en el testimonio de un líder: «la gente es como Palmira, es una antes y otra después de Ritter. Ritter es casi Jesucristo en Palmira. Antes de Ritter todo estaba podrido, después de Ritter, todo bien» (intermediario 5, comunicación personal, agosto 3, 2019). 


\subsection{Hacer gestión}

En el argot político del Valle del Cauca, el intercambio de apoyo político por favores del más diverso tipo se denomina gestión. La acción política permanente de los brókeres está centrada en ella, lo que se traduce en una colección de sinónimos para la misma acción: gestionar, hacer gestión, patinar proyectos, hacer favores. En los testimonios recolectados, gestión es básicamente sinónimo de política y poder. Un candidato lo señaló enfáticamente: el éxito del movimiento dependía completamente de la gestión de los líderes, quienes deben estar prestos en todo momento a patinarle favores a sus votantes (candidato 1, comunicación personal, mayo 29, 2019). Coincide esta práctica con las redes de resolución de problemas que Auyero (2001, pp. 93-129) señala para el conurbano bonaerense.

Los favores pueden ser de las más variadas dimensiones, desde becas universitarias o recomendaciones laborales, hasta diligencias ante empresas de servicios públicos, uniformes para el equipo de fútbol o el grupo de la tercera edad del barrio, incluso sillas para la iglesia o remesas para una celebración especial. Un intermediario local describe así las actividades y la forma de recruiting de la facción:

Ellos [los líderes] pillan quién es el que se mueve en el barrio, quién es el que mueve gente, a ese le llegan, algo le ofrecen: un parque, la solución para tus problemas, un poste, el alumbrado, el acueducto, hay gente que le han arreglado la casa, ¡marica! Te ofrecen, pero vos tenés que cumplir con organizar la reunión, ellos te ponen todo, las sillas, el refrigerio, a veces pagan por asistente veinte lucas [COL $\$ 20$ 000] para que asistan. Entonces vos como líder, vos lo que hacés es irte al barrio, megafoniar, sacar a la gente, hacer la reunión. [...] Eso hacen con... no sé cuántos, pero con la mayoría de los líderes sociales de los barrios de acá, que se mueven en la política, ellos saben que cada cuatro años hay algo y que lo que tienen es que convocar las reuniones, Ilamar gentes y garantizar votos. En todas las elecciones estar pendientes, recoger al amigo, decirle "ìya votó, vecina?», esto, lo otro, llamar para que le manden un carro (intermediario 5, comunicación personal, agosto 3, 2019).

La dimensión del acto de gestionar sobre los resultados electorales de la facción es destacada por los candidatos: 
Cuando salimos a la calle o incluso cuando nos contactan porque creen que tenemos las herramientas para hacer gestiones o representar a alguien en algunas gestiones, y eso es positivo porque uno dice, hombre, si me buscan es porque en algunos momentos hemos sido asertivos en brindar una ayuda o hacer una representación, una gestión por la comunidad (candidato 2, comunicación personal, mayo $29,2019)$.

En este contexto tiene particular importancia el testimonio de un intermediario que es al tiempo funcionario público y líder barrial (intermediario 6, comunicación personal, agosto 21, 2019). Surgido del liderazgo comunal en uno de los barrios más violentos de Palmira, ha logrado un ascenso exitoso que le permite contar con estudios de posgrado y participar de instancias claves de la toma de decisiones del municipio. Su orgullo personal se centra en haber participado del diseño y puesta en marcha de políticas públicas que para él fueron altamente participativas y beneficiaron su reconocimiento en sectores populares del municipio. Este bróker ha sistematizado su propia experiencia como gestor, dividiéndola en tres momentos sucesivos: primero, el intermediario que lleva la voz de la comunidad a la Administración; segundo, la intermediación comunidad-Estado, a la que denomina las gestiones diarias; y, finalmente, lograr en algún momento de su trayectoria ser al mismo tiempo Estado y comunidad, esto es, ser un referente. Para él, las dos primeras pueden ser llevadas a cabo por los líderes de base, pero para la tercera se requiere de ascenso dentro de la función pública, para lo cual es clave tener un concejal - fenómeno que se describe a continuación-. Así pues, en un escenario ideal, el bróker en ascenso logra finalmente ser electo concejal.

A pesar del reconocimiento local adquirido, el intermediario en cuestión señala que no se siente seguro de candidatizarse al Concejo pues, asegura, el éxito electoral del caicedismo es, hasta cierto punto, contraproducente: las listas son extremadamente competitivas y hacerse elegir es incierto. El testimonio de este bróker parece contrariar, de cierta manera, a Cendales, Olaya y Duncan (2019), en tanto se trata de una narrativa de la administración pública en donde intermediación política, ascenso social y ejercicios participativos pueden converger.

\subsection{Tener un concejal}

En conexión con lo anterior, tener un concejal se convirtió en una especie de señal de los tiempos del auge caicedista. El intercambio de votos 
por cargos públicos, práctica señalada por los intermediarios como de vieja data en el municipio y que ha atravesado a la mayoría de las facciones políticas locales, parece ampliarse y naturalizarse desde 2008. La inminencia de las elecciones locales pone en discusión la continuidad laboral del funcionariado y el pertenecer a la red de algún concejal aumenta las probabilidades de mantener el cargo. Un empleado del municipio recuerda de manera anecdótica la vida de oficina en medio de la coyuntura electoral: «Una de las funcionarias de planta, nombradas por concurso, se paró a decir "los que no tengan concejal me avisan". [...] Y eso, todo el mundo te pregunta para saber si tenés concejal: “ia vos quién te puso?", "ivos con quién estás?", “iquién es tu candidato?"» (intermediario 5, comunicación personal, agosto 3, 2019).

La capacidad de repartir cargos de la Alcaldía por parte de los concejales caicedistas durante el auge del movimiento es destacada por sus mismos integrantes: «Acá creo que el $100 \%$ de la planta es gente recomendada que en algún momento después se abrió concurso, concursó y quedó. [...] Eso es lo que me han dicho ahí: usted puede concursar, pero si no tiene concejal no va a ganar el concurso» (intermediario 5, comunicación personal, agosto 3, 2019). El compromiso de los funcionarios que tienen concejal se resume en cultivar un número concreto de votos que son trazables a partir de la entrega de listados de «familia y amigos» a los intermediarios respectivos y de compartir en grupos de WhatsApp selfies de asistencia a reuniones y mítines.

Las células —en tanto estructuras medianamente estables y con perspectivas de perdurar en el tiempo- y gestionar — esto es, intercambiar por favores en el mediano o en el largo plazo- parece remitir más al esquema del clientelismo relacional que al del clientelismo electoral (Nichter, 2010).

\subsection{La calle caicedista}

Los repertorios públicos del caicedismo coinciden con los análisis del enfoque informacional. Los intermediarios señalan que las grandes manifestaciones no son la práctica más común de la facción —en tanto cuestan mucho y no garantizan votos trazables, coincidiendo entonces con sus pares peruanos estudiados por Muñoz (2014)_, prefiriéndose otras como el caseo. Esta última es una de las prácticas electorales más exitosas del caicedismo: se trata de una campaña casa a casa encabezada por el candidato, enfocada en hogares seleccionados de «familia y amigos». Las visitas duran menos de cuarenta minutos, tiempo durante el cual el candidato presenta su programa 
y establece una relación personal directa con el elector. Según los testimonios, el resultado es exitoso: se amplía la base electoral y los candidatos ganan una relación directa que puede resumirse en la siguiente frase recurrente de uno de ellos: "yo no voy a cambiar mi número de WhatsApp, siempre les voy a contestar» (candidato 1, comunicación personal, mayo 29, 2019). Un intermediario lo recuerda de la siguiente manera:

Vos hacés una reunión en masa de doscientas personas, pero la gente no te está escuchando, es un político más, voy por el refrigerio, ahí me cuadré el desayuno, bueno, lo que sea o me dieron veinte lucas por ir y eso te sirve. Este man [un candidato caicedista] tiene esa estrategia del caseo y la gente siente que el man no es el politiquero cualquiera, sino que el man te va a escuchar a tu casa. Y uno con esa doctoritis tan hijueputa que maneja pues claro, imarica!: el concejal vino a mi casa, se sentó en mi sala, en mis muebles, habló conmigo, me saludó. [...] Creo que es una estrategia muy buena, muy buena, porque la gente le ha copiado mucho. Yo no he visto que él haga reuniones grandes, masivas todavía. Gran parte de su agenda ha sido estar todo el día en la casa de tu amiga, en la casa de mamá, de tu abuelita, de tu vecino, en la casa de todo el mundo, hablando con la gente (intermediario 5, comunicación personal, agosto 3, 2019).

Sin embargo, la coyuntura de las elecciones locales permite el despliegue de un repertorio de «demostración de poder», como ocurrió en la marcha del 26 de julio de 2019. En ella cerca de cuatro mil personas acompañaron la inscripción de la candidatura caicedista de Luis Alfonso Chávez a la Alcaldía. Columnas de simpatizantes de los candidatos al Concejo desfilaron ordenadamente junto a organizaciones sociales diversas: barras bravas, grupos de danza y de la tercera edad, activistas LGBTI, animalistas y evangélicos. En las márgenes, líderes y referentes tomaban nota de la asistencia del personal mediante recurrentes selfies que se difundieron posteriormente en grupos de WhatsApp. Un funcionario recuerda la asistencia de esta manera:

Pues el día de la marcha, pues como la mayoría de la Alcaldía, sino toda, está con el candidato, pues él iba a hacer la inscripción de la candidatura, nos dejaron salir a las 2 , digamos al mediodía, porque salimos a las 12 y nadie volvió a las 2 . Todo el mundo tenía permiso para asistir a la movilización a apoyar al candidato. Sí fue raro, la Alcaldía quedó vacía, todos los procesos se pararon por ir a apoyar al candidato. [...] Mirá el total de empleados son como 570 de planta y contratistas como mil y pico. Son como unos 1300 en total. Contratistas, estoy casi que segura que todos estaban allá porque ellos 
tienen el puesto mucho más inestable. Y empleados de planta, digamos que son 500, unos 490 podía haber en la marcha (intermediario 5, comunicación personal, agosto 3, 2019).

Asimismo, durante la campaña para las elecciones locales de 2019 fue posible dar cuenta de por lo menos una actividad pública por semana entre febrero y octubre. En ellas participaron los candidatos al Concejo, a la Alcaldía y a la Asamblea, y en ocasiones la candidata a la gobernación del Valle, Clara Luz Roldán, así como el senador Ritter López. El repertorio de estas fue amplio: caminatas, ferias deportivas, ciclopaseos, jornadas de aeróbicos, zumba y de esterilización de mascotas, entre otros.

Por su parte, los cierres de campaña de 2019 sí siguieron el modelo típico de plaza pública: tarima, animadores, refrigerios, orquestas y humoristas. Los objetivos de estas actividades son dos: de un lado, generar recordación entre los votantes, pues, según un candidato, a la hora de marcar el tarjetón la mayoría de las personas se confunden u olvidan por quién votar (candidato 2, comunicación personal, mayo 15, 2019). Esto es notorio en la repetición permanente de los nombres de los candidatos y su número en el tarjetón, así como del logo y de los colores del partido. El otro objetivo, «mostrar músculo»:

Siento que para muchos candidatos el hecho no es la reunión por el hecho de que necesitan los votos porque ya tienen todo ganado, sino que necesitan medir fuerzas, entonces si vos mostrás una foto de una reunión con un montón de gente y el otro candidato que es oposición muestra una con un poquitico de gente, pues vos estás midiendo fuerza de que vos tenés con qué, sobre todo de imagen (intermediario 5, comunicación personal, agosto 3, 2019).

La importancia de esta dimensión informacional coincide nuevamente con las conclusiones del trabajo de Muñoz (2014), como lo demuestra una cadena de WhatsApp de la campaña de un candidato al Concejo:

Hola buenos días, feliz inicio de semana, recuerda que este sábado es nuestro gran cierre, no dejes de invitar a tus amigos, ejemplo si quieres llevar 50 personas debes invitar $100, ;)$, si quieres que [sic] llevar 20 debes invitar 40 , es vital que nos vaya bn en el cierre, el cierre es un tentativo del dia [sic] electoral, no podemos ser inferiores a otras campañas, tenemos con que ser si no el mejor cierre, si uno de los mejores, vamos con toda, cuento contigo y con toda tu familia y amigos (cadena de WhatsApp, comunicación personal, agosto 20, 2019). 


\section{Una narrativa de la permanencia del caicedismo en el poder local}

Es importante tomar en cuenta los discursos que construye y difunde la facción, básicamente una narrativa sobre la eficacia y los logros de sus administraciones basada en: a) las alcaldías previas eran corruptas; b) las administraciones del caicedismo ejecutan obras de infraestructura de alto impacto; c) los tres alcaldes son mandatarios «que se notan», que tienen carisma y liderazgo local, en contraposición con alcaldes previos que «nadie se acuerda de ellos»; d) las administraciones caicedistas logran volver a poner a Palmira «en el mapa"».

En este marco, la administración de Raúl Arboleda (2008-2011) es descrita como la del líder que construye predominio a través de las alianzas políticas y la vinculación de los líderes locales no alineados con el motoísmo. Al tiempo, en el plano de la narrativa caicedista, es la administración que libra una gesta contra el Gobierno central para lograr la salida del municipio de la Ley de Quiebras. La capacidad de ganar liderazgos sociales e incidir en el plano local se multiplicó con el acceso a la Alcaldía, incrementándose la incidencia de las células y «ganándole gente» a las maquinarias rivales. El

[244 ] trabajo de base se veía respaldado por la institucionalidad local, que permitía contar con recursos para el desarrollo de diversas iniciativas.

Entre los líderes barriales el ideal de la prosperidad y el ascenso social a través de la militancia caicedista se fue extendiendo. Un funcionario público, originalmente líder juvenil en un asentamiento local, recuerda cómo durante la administración Arboleda «tocó las puertas» de una maquinaria competidora del caicedismo y que «nunca le cumplieron»; por el contrario, al acercarse a los dirigentes caicedistas encontró «gente seria», que «permite crecer» (intermediario 6, comunicación personal, agosto 21, 2019). En ese marco, la ampliación de las redes clientelares de la facción, ahora beneficiaria del poder local, fue superlativa a ojos de la misma militancia: un informante sostiene que paulatinamente el caicedismo fue capaz de construir una fortaleza dentro de la burocracia de la Alcaldía y de entes territoriales.

La administración de Ritter López (2012-2015) se caracterizó por la ejecución de los recursos acopiados por la anterior, la de las grandes obras como la reapertura del Teatro Materón, la reforma de la Unidad Deportiva, la peatonalización del centro y la creación de la plataforma de transporte Tupal. 
Asimismo, se alcanzó la figuración del municipio e n el ámbito nacional: López fue electo como el mejor alcalde del país en la categoría de ciudades intermedias (El Tiempo, 2015, diciembre 5). Dicha administración es considerada «dialogante», en tanto López logró una «tregua» con el motoísmo y entregó cuotas de burocracia municipal a la oposición:

En el ejercicio de Ritter López se hizo un ejercicio muy positivo: el llamó a la unidad a los distintos grupos opositores en campaña y les dio una representación y les dio una importancia dentro de su mandato y eso permitió que se gobernara para toda una ciudad, no solo para el caicedismo, como el partido Nueva Generación-caicedista, sino que aquí hubo cabida para todos (candidato 1, comunicación personal, mayo 29, 2019).

Es en ese periodo en que se fortalecieron dos de los elementos más interesantes de la lógica de las células del caicedismo: por un lado, el carácter competitivo de la relación entre células, por ejemplo, con el crecimiento del movimiento, una misma manzana podía contar con dos o tres líderes de distintas células; por el otro, el carácter personalista y disciplinado de la facción. El resultado es el de una maquinaria capaz de romper clivajes locales tradicionales, como los de clase o ideología, tal y como lo demuestra el trabajo de Arce (2018) o el testimonio de un analista local contrario al caicedismo:

En Palmira, esa división política de clase se acabó en los ochenta, cuando barrios como Zamorano, María Cano, eran los fortines del Partido Comunista y la UP. Las Mercedes, Mirriñao y partes del centro eran conservadores. Y el resto, San Pedro, La Emilia, Colombia, los barrios tradicionales, populares, más antiguos, con casa de teja y patio grande, eran liberales de raca mandaca. [...] Pero hoy en día, en cualquier barrio que vaya, en cualquier puesto, te gana el caicedismo fácilmente (analista local, comunicación personal, julio 18, 2019).

En el mismo sentido, un candidato caicedista explicó este proceso de la siguiente manera: a partir de las últimas reformas políticas, las viejas maquinarias perdieron relevancia. Para él, hoy hay mucho más margen de decisión ciudadana, lo cual es un reto grande para todas las facciones políticas: las que no se adaptan, desaparecen. Así, pone un ejemplo muy ilustrativo: a pesar del enorme predominio de la maquinaria de su facción, en las dos vueltas de las elecciones presidenciales de 2018 los candidatos que el caicedismo apoyó perdieron en el municipio (intermediario 3, comunicación 
personal, mayo 15, 2019). ${ }^{6}$ Dicha lectura coincide con la de un analista local: el electorado palmirano es «muy político» y se «mueve mucho», ${ }^{7}$ la ciudad no tendría ni nombres ni maquinarias inamovibles (analista local, comunicación personal, julio 19, 2019), lo que le añade valor a la capacidad de crecimiento y permanencia del caicedismo.

En el tramo final de la administración López, el caicedismo logró la elección de Elbert Díaz como representante a la Cámara, en el primer capítulo del mentado efecto de arrastre derivado del predominio local (Núñez, 2018).

Finalmente, en las entrevistas realizadas se encontró que la alcaldía de Jairo Ortega Samboní (2016-2019) es la menos popular de las tres consecutivas: ${ }^{9}$ de un lado, por medidas antipopulares entre las que se destacan aquellas contra el mototaxismo; y del otro, por la consolidación de una oposición heterogénea unida en torno a una narrativa anticaicedista exitosa $^{10}$ — la del continuismo de la corrupción y la rosca (camarilla) — que se vio fortalecida por las victorias locales de Sergio Fajardo y Gustavo Petro en las elecciones presidenciales y que finalmente derrotaría al heredero caicedista, Luis Alfonso Chávez, en las locales de 2019. A pesar de esto, en el tramo final de la administración Ortega el caicedismo logró la exitosa elección de [246] la fórmula Elbert Díaz-Ritter López al Congreso y la de Hugo Perlaza a la Asamblea. ${ }^{11}$

\footnotetext{
${ }^{6}$ En la primera vuelta, Germán Vargas Lleras (Cambio Radical) solo logró 12037 votos, ubicándose en la cuarta votación local; en segunda vuelta, Iván Duque (Centro Democrático) obtuvo 51 138, casi $20 \%$ por debajo de Gustavo Petro (Colombia Humana).

Los resultados de las elecciones locales de 2019, con la derrota de Luis Alfonso Chávez contra Oscar Escobar del partido Alianza Verde - a pesar del buen desempeño caicedista en Concejo y Asamblea - demuestran ese carácter, abriéndose la puerta a un reacomodamiento radical de la política local.

${ }^{8}$ En este artículo se omitió de la relación entre Alcaldía y Gobernación; sin embargo, es pertinente tener en cuenta que la administración de Ortega Samboní coincidió con la gobernación de Dilian Francisca Toro, en un periodo de crecimiento y consolidación de Nueva Generación en todo el departamento (Duque, 2018, febrero 18)

${ }^{9}$ Paradójicamente, pues ocurre en el contexto de mejor rendimiento electoral de la facción, donde alcanza niveles de predominio local: $55 \%$ de la votación a Alcaldía y diez concejales electos — cuando los resultados de las dos elecciones previas eran de 35,33\% y 49,84\% y de 9 y 5 sillas en el Concejo, respectivamente (Registraduría Nacional del Estado Civil, s. f.)—. Igualmente, Ortega también fue nominado como uno de los mejores alcaldes del país (El País, 2019, 17 de julio).

${ }^{10}$ La oposición incluía a Cambio Radical, la Alianza Verde, el Centro Democrático, el Polo Democrático Alternativo y la Colombia Humana.

${ }^{11}$ Con 37877 votos en el departamento, 23437 de ellos en Palmira (Registraduría Nacional del Estado Civil, s. f.).
} 


\section{Conclusiones}

Los intermediarios electorales fueron actores clave del proceso de construcción de la maquinaria de la facción caicedista en Palmira durante el periodo del acceso de esta al poder local. Estos hombres y mujeres de distinto origen social construyeron el espinazo de una colectividad disciplinada y competitiva, cuyo comportamiento reta a las construcciones teóricas habituales en este campo.

Frente a ello, si bien este estudio no se fundamenta en un diseño de theory-testing, sí aporta evidencia para discusiones teóricas abiertas. En primer lugar, frente a la tipología de clientelismo propuesta por Nichter (2010) — electoral contra relacional—, el caso de Palmira parece remitir más a un clientelismo relacional afincado en relaciones de larga duración que, de diversas maneras, superan un simple intercambio de favores por votos. Es, por tanto, precedente para analizar el comportamiento clientelar subnacional en contextos de sistemas de partidos desinstitucionalizados. Igualmente, la maquinaria horizontal-competitiva y su esquema de células difieren del modelo de redes de círculos concéntricos (Auyero, 2001), por lo que se hace pertinente avanzar en reflexiones teóricas mayores.

En el mismo sentido, frente a la relación entre continuidad de la facción y la degradación de la política pública local (Cendales, Olaya y Duncan, 2019), el trabajo de campo recoge impresiones contraintuitivas de actores de esta última que sostienen la existencia de políticas públicas participativas ligadas a la intermediación de los brókeres y al respaldo en la administración. Esto merece una comprobación cuantitativa posterior.

Finalmente, frente a la discusión sobre las consecuencias del acceso de la facción a la Alcaldía planteado por Núñez (2018), para este caso específico se asiste tanto a la tendencia a la continuidad en el poder local — por tres periodos - como a los efectos de arrastre sobre integrantes de la facción que resultaron electos a otros cargos: Elbert Díaz a la Cámara, Ritter López al Senado y Hugo Perlaza a la Asamblea.

Otra perspectiva de investigación futura se deriva de la derrota de la facción en las elecciones locales de 2019 y su reacomodamiento como oposición en la alcaldía entrante. El seguimiento de esta nueva etapa del caicedismo seguramente permitirá un contraste efectivo para las conclusiones de este trabajo. 


\section{Referencias bibliográficas}

1. Albarracín, Juan; Gamboa, Laura \& Mainwaring Scott. (2018). Deinstitutionalization without Collapse: Colombia's Party System. In: Mainwaring Scott (Ed.). Party Systems in Latin America: Institutionalization, Decay, and Collapse (pp. 227-254). Cambridge: Cambridge University. https://doi. org/10.1017/9781316798553.009

2. Arce, Tania. (2018). Análisis de las preferencias políticas de los votantes según su estrato socioeconómico en las elecciones a la Alcaldía municipal de Palmira 20072015. (Tesis inédita de pregrado). Universidad Icesi, Cali.

3. Auyero, Javier. (1996). Me manda López. La doble vida del clientelismo político. Debate, 37, pp. 221-229.

4. Auyero, Javier. (2001). La política de los pobres. Las prácticas clientelares del peronismo. Buenos Aires: Manantial.

5. Auyero, Javier y Benzecry, Claudio. (2016). La lógica práctica del dominio clientelista. Revista Mexicana de Ciencias Politicas y Sociales, 61 (226), pp. 221-246. https://doi.org/10.1016/S0185-1918(16)30009-5

6. Berenschot, Ward \& Bagchi, Sarthak. (2019). Comparing Brokers in India: Informal Networks and Access to Public Services in Bihar and Gujarat. Journal of Contemporary Asia, 50 (3), pp. 457-477. https://doi.org/10.1080/00472336.2019.1 605535

7. Boas, Taylor C. \& Smith, Amy Erica. (2019). Looks Like Me, Thinks Like Me: Descriptive Representation and Opinion Congruence in Brazil. Latin American Research Review, 54 (2), pp. 310-328. https://doi.org/10.25222/larr.235

8. Cámara de Comercio de Palmira. (2017). Situación económica de Palmira y su área de influencia (Pradera, Florida y Candelaria). Año 2017. Recuperado de https:// www.ccpalmira.org.co/portal/images/Docs/Situacion_economica/SITUACION\%20 ECONOMICA\% 202017.pdf

9. Cendales, Andrés; Olaya, Jorge \& Duncan, Gustavo. (2019). Narrative on Local Democracies, Government, and Public Policy in the Colombian Pacific. In: Cendales, Aandrés; Pinto, Angela; Mora, John James \& Guerrero, Hugo (Eds.). Analytical Narrative on Subnational Democracies in Colombia. Clientelism, Government and Public Policy in the Pacific Region (pp. 11-64). New York: Springer.

10. Cendales, Andrés; Guerrero, Hugo; Wilches, Jaime \& Pinto, Angela. (2019). Introduction. The Paradox of a Formally Open and Materially Exclusive Democracy. In: Cendales, Andrés; Pinto, Angela; Mora, John James \& Guerrero, Hugo (Eds.). Analytical Narrative on Subnational Democracies in Colombia. Clientelism, Government and Public Policy in the Pacific Region (pp. 1-10). New York: Springer. https://doi.org/10.1007/978-3-030-13009-1_1

11. Dávila, Andrés. (1999). Clientelismo, intermediación y representación política en Colombia: ¿qué ha pasado en los noventa? Estudios Políticos, 15, pp. 61-78. 
12. De León, Alfredo. (2011). Penumbras y demonios en la política colombiana: Un análisis sobre el clientelismo. Bogotá, D. C.: Desde Abajo.

13. Delgado Madroñero, Johnny. (2011). El bandolerismo en el Valle del Cauca 1946-1966. Cali: Gobernación del Valle del Cauca.

14. Departamento Administrativo Nacional de Estadística (DANE). (2019). Valor agregado y actividades económicas-municipios (2016-2017 provisional). Recuperado de https://dane.maps.arcgis.com/apps/MapSeries/index.html?appid=11e3d747a6f74 od6a345e84634412813

15. Duque, Tatiana. (2018, febrero 18). Luego de conquistar Palmira el "caicedismo» quiere Senado. La Silla Vacía. Recuperado de http://lasillavacia.com/ silla-pacifico/luego-de-conquistar-palmira-el-caicedismo-quiere-senado-64735

16. Duque, Tatiana. (2019, octubre 2). La hegemonía del «caicedismo» de Dilian en Palmira, a prueba. La Silla Vacía. Recuperado de https://lasillavacia.com/sillapacifico/hegemonia-del-caicedismo-dilian-palmira-prueba-73766

17. Durazo, Julián. (2012). Clientelism and Subnational Politics in Latin America. Reflections on Oaxaca (Mexico) and Bahía (Brasil). In: Hilgers, Tina (Ed.). Clientelism in Everyday Latin American Politics (pp. 122-136). New York: Palgrave Macmillan.

18. El País. (2019, 17 de julio). Alcalde de Palmira nominado como uno de los mejores diez mandatarios de Colombia. Recuperado de http://www.elpais.com.co/ valle/alcalde-de-palmira-nominado-como-uno-de-los-mejores-diez-mandatarios-decolombia.html

19. El Tiempo. (2006, enero 16). Palmira fue la gran plaza roja. Recuperado de https://www.eltiempo.com/archivo/documento/MAM-1885795

20. El Tiempo. (2015, diciembre 5). «Dejamos una Palmira encarrilada en el siglo 21». Recuperado de https://www.eltiempo.com/archivo/documento/CMS-16450051

21. Eufracio Jaramillo, Jorge Federico. (2019). Comprendiendo el clientelismo mediante etnografía. Redes y operación política en Autlán de Navarro (Jalisco) durante las elecciones de 2012. En: González Tule, Luis Antonio (dir.). Clientelismo, patronazgo y corrupción en Colombia y México (pp. 221-247). Barranquilla: Universidad del Norte. https://doi.org/10.2307/j.ctvh9w17d.13

22. Gaitán Cruz, Sol Alejandra. (s. f.). Análisis del mapa político del Valle del Cauca. En: López, Claudia (ed.). Monografía político electoral. Departamento del Valle del Cauca. 1997 a 2007 (pp. 36-89). Bogotá, D. C.: MOE.

23. Gallego, Jorge. (2018). Natural Disasters and Clientelism: The Case of Flood and Landslides in Colombia. Electoral Studies, 55, pp. 73-88. https://doi.org/10.1016/j. electstud.2018.08.001

24. García Villegas, Mauricio y Revelo Rebolledo, Javier Eduardo. (2010). Estado alterado. Clientelismo, mafias y debilidad institucional en Colombia. Bogotá, D. C.: Dejusticia.

25. García, Ana Cristina y Gaviria, Anderson David. (2015). Radiografía del poder político en Guacarí: estudio de caso de la red clientelar de Carlos Herney Abadía. 
(Tesis inédita de pregrado). Universidad del Valle, Cali. Recuperado de https:// bibliotecadigital.univalle.edu.co/bitstream/handle/10893/9517/3489-0510626. pdf? sequence $=1$ \&isAllowed $=y$

26. Gerring, John. (2012). Social Science Methodology. A Unified Framework. New York: Cambridge University. https://doi.org/10.1017/CBO9781139022224

27. González, Luis Antonio; Guzmán, Carlos Enrique \& Tuirán, Ángel. (2019). Clientelismo de mediación en Barranquilla. En: González Tule, Luis Antonio (dir.). Clientelismo, patronazgo y corrupción en Colombia y México (pp. 54-74). Barranquilla: Universidad del Norte. https://doi.org/10.2307/j.ctvh9w17d.7

28. Guerrero Apráez, Víctor. (2013). Hacia una aproximación comparativa de las Guerras Civiles de 1876-77 y los Mil Días. Papel Político, 18 (2), pp. 549-583.

29. Guerrero García, Laura Daniela. (2014). Clientelismo político, ¿desviación de la política o forma de representación?: Estado del arte sobre las aproximaciones al clientelismo en Colombia 1973-2011. Bogotá, D. C.: Universidad del Rosario.

30. Hagene, Turid. (2018). The Power of Ethnography: A Useful Approach to Researching Politics. Forum for Development Studies, 45 (2), pp. 305-325. https://doi. org/10.1080/08039410.2017.1366360

31. Johnston, Michael. (1979). Patrons and Clients, Jobs and Machines: A Case Study of the Uses of Patronage. The American Political Science Review, 73 (2), pp. 385-398. https://doi.org/10.2307/1954886

32.Kadfak, Alin. (2019). Intermediary Politics in a Peri-Urban Village in Mangaluru,

[250] India. Forum for Development Studies, 46 (2), pp. 277-298. https://doi.org/10.1080/0 8039410.2018.1529700

33. Leal, Francisco y Dávila, Andrés. (2010). Clientelismo: el sistema político y su expresión regional. Bogotá, D. C.: Universidad de los Andes.

34. Milanese, Juan Pablo y Barrero, Fredy A. (2016). Selección de candidatos en escenarios de atomización dirigencial. Análisis de los casos de Cali y el Valle del Cauca, elecciones locales y regionales 2015. Análisis Político, 88, pp. 69-89. https:// doi.org/10.15446/anpol.v29n88.63602

35. Muñoz, Paula. (2014). An Informational Theory of Campaign Clientelism: The Case of Peru. Comparative Politics, 47 (1), pp. 79-98. https://doi. org/10.5129/001041514813623155

36. Murillo, Andrés Felipe. (2015). La diáspora del castillo de cristal: las disputas fraccionales y la hiperfragmentación del Partido Liberal, en medio de la herencia frentenacionalista. 1982-1990. El caso de Cali. (Tesis inédita de pregrado). Universidad del Valle, Cali. Recuperado de https://bibliotecadigital.univalle.edu.co/ xmlui/bitstream/handle/10893/9454/3489-0510746.pdf?sequence = 1

37. Nichter, Simeon Charaka. (2010). Politics and Poverty: Electoral Clientelism in Latin America. (Doctoral Thesis). Berkeley: University of California.

38. Núñez, Lucas. (2018). Do Clientelistic Machines Affect Electoral Outcomes? Mayoral Incumbency as a Proxy forMachineProwess. ElectoralStudies, 55, pp. 109-119. 
39. Ocampo, Gloria Isabel. (2014). Poderes regionales, clientelismo y Estado: etnografías del poder y la política en Córdoba, Colombia. Bogotá, D. C.: CINEP, Odecofi, Colciencias. https://doi.org/10.1016/j.electstud.2018.08.010

40. Ortiz de Rozas, Victoria. (2017). Clientelismo, territorio y política subnacional en Argentina . Aportes a partir del caso de Santiago del Estero. Colombia Internacional, 90, 127-156. https://doi.org/10.7440/colombiaint90.2017.05

41. Pérez, Aníbal y Luján, David. (2018). Cercanía, favor, lealtad. Clientelismo en dos municipalidades chilenas. Sociológica, 94, pp. 235-268.

42. Pino, Juan Federico y Cárdenas, Javier Alonso. (2016). El clientelismo: el incesante juego de políticos y clientes en la construcción y reproducción de la democracia subnacional y nacional. Reflexión Política, 35, pp. 58-70. https://doi. org/10.29375/01240781.2464

43. Registraduría General del Estado Civil. (s. f.). Histórico de resultados. Recuperado de https://www.registraduria.gov.co/-Historico-de-Resultados,3635-.html

44. Sáenz, José Darío. (2010). Élite política y construcciones de ciudad. Cali 1958-1998. Cali: Universidad Icesi.

45. Schneider, Mark. (2019). Do Local Leaders Know their Voters? A Test of Guessability in India. Electoral Studies, 61, pp. 1-12. https://doi.org/10.1016/j. electstud.2019.102049

46. Scott, James C. (1969). Corruption, Machine Politics, and Political Change. The American Political Science Review, 63 (4), pp. 1142-1158. https://doi.org/10.1017/ S0003055400263247

47. Stokes, Susan C.; Dunning, Thad; Nazareno, Marcelo \& Brusco, Valeria. (2013). Brokers, Voters, and Clientelism: The Puzzle of Distributive Politics. New York: Cambridge University. https://doi.org/10.1017/CBO9781107324909

48. Valencia Llano, Alonso. (2019). Palmira: historia, desarrollo económica e identidad cultural. Cali: Universidad del Valle. https://doi.org/10.2307/j.ctv14jx727

49. Zapata, Eucaris. (2016a). Clientelismo político. Un concepto difuso pero útil para el análisis de la política local. Estudios Políticos, 49, pp. 167-185.

50. Zapata, Eucaris. (2016b). El clientelismo político como mecanismo de intermediación. El caso de Rionegro, 2000-2011. Reflexión Política, 36, pp. 178-193. https://doi.org/10.29375/01240781.2660

51. Zarazaga, Rodrigo. (2014). Brokers Beyond Clientelism: A New Perspective Through the Argentine Case. Latin American Politics and Society, 56 (3), pp. 23-45. https://doi.org/10.1111/j.1548-2456.2014.00238.x

52. Zariski, Raphael. (1960). Party Factions and Comparative Politics: Some Preliminary Observations. Midwest Journal of Political Science, 4 (1), pp. 27-51. https://doi.org/10.2307/2108754 